\title{
Enriquecimento proteico do resíduo da goiaba (Psidium guajava L.) por meio da
}

\section{fermentação semissólida}

\author{
Protein enrichment of guava residue (Psidium guajava L.) through semi-solid fermentation \\ Enriquecimiento proteico del residuo de guayaba (Psidium guajava L.) mediante fermentación \\ semisólida
}

Recebido: 20/10/2021 | Revisado: 27/10/2021 | Aceito: 03/11/2021 | Publicado: 06/11/2021

Sara Morgana Felix de Sousa

ORCID: https://orcid.org/0000-0003-1019-0760

Universidade Federal de Campina Grande, Brasil E-mail: saramfs@hotmail.com

Rosenildo dos Santos Silva

ORCID: https://orcid.org/0000-0002-8728-9075

Universidade Federal de Campina Grande, Brasil

E-mail: rosenildo.sb@gmail.com

Osvaldo Soares da Silva

ORCID: https://orcid.org/0000-0002-4608-0638

Universidade Federal de Campina Grande, Brasil

E-mail: osvaldo_so2002@yahoo.com.br

Alison dos Santos Oliveira

ORCID: https://orcid.org/0000-0003-2874-0353

Universidade Federal de Campina Grande, Brasil E-mail: alisonpb20@gmail.com

Lídia Paloma da Silva Nogueira

ORCID: https://orcid.org/0000-0002-1124-7602

Universidade Federal de Campina Grande, Brasil

E-mail: lidiapaloma28@gmail.com

Maria Eduarda Paz de Lima

ORCID: https://orcid.org/0000-0002-8131-9763

Universidade Federal de Campina Grande, Brasil

E-mail: dudespqs@gmail.com

Morgana Aragão Araújo

ORCID: https://orcid.org/0000-0001-6727-2770

Universidade Federal de Campina Grande, Brasil

E-mail: morganaaragao@hotmail.com

Jonnathan Silva Nunes

ORCID: https://orcid.org/0000-0002-9763-9227

Universidade Federal de Campina Grande, Brasil

E-mail: jonnathan.s.n@hotmail.com

\section{Resumo}

Os resíduos decorrentes das atividades agroindustriais são provenientes, principalmente, do processamento de frutas para produção de polpas. O aproveitamento desses resíduos se mostra frente ao desperdício de alimentos como uma grande oportunidade de desenvolvimento de subprodutos. Dentre os diferentes resíduos agroindustriais o resíduo de goiaba se destaca por apresentar em sua composição de vitaminas, minerais, fibras e compostos antioxidantes importantes para as funções fisiológicas. O objetivo deste trabalho foi estudar o processo de enriquecimento proteico do resíduo da goiaba com a utilização da levedura Saccharomyces cerevisiae, por meio de fermentação semissólida. O resíduo da goiaba foi triturado e em seguida colocado em um biorreator retangular com $12 \% \mathrm{~m} / \mathrm{m}$ da levedura e acondicionado em uma estufa com circulação de ar forçada a $35{ }^{\circ} \mathrm{C}$ de temperatura, durante 21 horas. Foram feitas pesagens dessas amostras nos intervalos de $0,3,6,9,12,15,18$ e 21 horas de fermentação e monitorados em cada intervalo as análises do teor de água, proteínas e sólidos solúveis totais. De modo geral é possível concluir que a fermentação semissólida empregada no resíduo da goiaba, com a utilização da levedura Saccharomyces cerevisiae, possibilitou o aumento no teor de proteína do resíduo com o tempo de fermentação, tendo as maiores concentrações às 3 e 6 horas. Assim é possível afirmar que a técnica empregada foi satisfatória no enriquecimento proteico do resíduo da goiaba, podendo ser utilizada como forma de aproveitamento de resíduos.

Palavras-chave: Aproveitamento de resíduo; Aumento nutricional; Proteína. 


\begin{abstract}
The residues resulting from agro-industrial activities come mainly from the processing of fruit for the production of pulp. The use of these residues is shown in the face of food waste as a great opportunity for the development of byproducts. Among the different agro-industrial residues, the guava residue stands out for presenting in its composition vitamins, minerals, fibers and antioxidant compounds that are important for physiological functions. The objective of this work was to study the process of protein enrichment of guava residue using the yeast Saccharomyces cerevisiae, through semi-solid fermentation. The guava residue was crushed and then placed in a rectangular bioreactor with $12 \%$ $\mathrm{m} / \mathrm{m}$ of yeast and stored in an oven with forced air circulation at $35^{\circ} \mathrm{C}$ temperature for 21 hours. These samples were weighed at intervals of $0,3,6,9,12,15,18$ and 21 hours of fermentation and the analyzes of water, protein and total soluble solids content were monitored at each interval. In general, it is possible to conclude that the semi-solid fermentation used in the guava residue, with the use of the yeast Saccharomyces cerevisiae, allowed the increase in the residue's protein content with the fermentation time, with the highest concentrations at 3 and 6 hours. Thus, it is possible to affirm that the technique used was satisfactory in the protein enrichment of the guava residue, and it can be used as a form of waste recovery.
\end{abstract}

Keywords: Waste utilization; Nutritional increase; Protein.

\title{
Resumen
}

Los residuos resultantes de las actividades agroindustriales provienen principalmente del procesamiento de frutas para la producción de pulpa. El uso de estos residuos se muestra ante el desperdicio de alimentos como una gran oportunidad para el desarrollo de subproductos. Entre los diferentes residuos agroindustriales, el de guayaba destaca por presentar en su composición vitaminas, minerales, fibras y compuestos antioxidantes importantes para funciones fisiológicas. El objetivo de este trabajo fue estudiar el proceso de enriquecimiento proteico del residuo de guayaba utilizando la levadura Saccharomyces cerevisiae, mediante fermentación semisólida. El residuo de guayaba se trituró y luego se colocó en un biorreactor rectangular con $12 \% \mathrm{~m} / \mathrm{m}$ de levadura y se almacenó en un horno con circulación de aire forzado a una temperatura de $35^{\circ} \mathrm{C}$ durante 21 horas. Estas muestras se pesaron a intervalos de 0, 3, 6, 9, 12, 15, 18 y 21 horas de fermentación y se controlaron los análisis de agua, proteína y contenido de sólidos solubles totales en cada intervalo. En general, es posible concluir que la fermentación semisólida empleada en el residuo de guayaba, con el uso de la levadura Saccharomyces cerevisiae, permitió aumentar el contenido de proteína del residuo con el tiempo de fermentación, con las concentraciones más altas a 3 y 6 . horas. Así, es posible afirmar que la técnica utilizada fue satisfactoria en el enriquecimiento proteico del residuo de guayaba, y puede ser utilizada como una forma de recuperación de residuos.

Palabras clave: Utilización de residuos; Incremento nutricional; Proteína.

\section{Introdução}

O Brasil possui grande destaque no setor da fruticultura, por possuir uma vasta extensão territorial, a diversidade do clima e do solo no país o colocam em uma posição privilegiada na produção de frutas em relação aos demais países do mundo (SEBRAE, 2015). Sabe-se que essa elevada produção de frutas resulta em uma grande quantidade de resíduos derivados de seu processamento.

Tendo conhecimento da grande quantidade de resíduos agroindustriais, surge a preocupação com o meio ambiente por parte das indústrias e comércio para a redução desses resíduos e/ou reaproveitamento do mesmo. Em vários lugares do mundo, instituições governamentais, assim como as indústrias estão se impulsionando para executar uma política de preservação ambiental, com o objetivo de minimizar os impactos gerados pelas indústrias. Parte desse impacto ambiental é decorrente da falta de planejamento das empresas em relação ao gerenciamento do descarte dos resíduos agroindustriais (Giordani Junior et al., 2014).

Os resíduos decorrentes das atividades agroindustriais são, em sua grande maioria, provenientes do processamento de frutas para produção de polpas, dependendo do tipo de fruta podem ser compostos por casca, caroço ou sementes e bagaço (Viana; Cruz, 2016). O aproveitamento desses resíduos se mostra frente ao desperdício de alimentos, e ao beneficiamento e processamento desses, uma grande oportunidade de desenvolvimento de subprodutos, como também agregação de valor perdido, e utilização sustentável desses resíduos. Diversas agroindústrias têm realizado o aproveitamento de resíduos na produção de subprodutos, atentando a agregação de valor deste (Costa Filho et al., 2017).

Dentre os diferentes resíduos agroindustriais o resíduo de goiaba (Psidium guajava L.) se destaca, por apresentar em 
sua composição de vitaminas, minerais, fibras e compostos antioxidantes importantes para as funções fisiológicas, fazendo com que esse resíduo tenha uma melhor perspectiva de utilização do ponto de vista nutricional (Sousa et. al.,2011). A goiaba, é uma das principais matérias primas utilizadas pela indústria brasileira, transformando-a em polpa, néctar, suco, compota, sorvete e doce (Souza et al., 2011).

Uma alternativa para o aproveitamento dos resíduos da goiaba é a utilização de tecnologias fermentativas. A fermentação é uma tecnologia fundamental para converter substratos, que apresentam alto conteúdo de lignina e baixa quantidade de proteínas, em materiais proteicamente enriquecidos. No processo de aumento do valor nutritivo de resíduos agroindustriais, a utilização de microrganismos como fontes de proteína unicelular para alterar diversos substratos durante sua atividade metabólica, é uma das formas preferidas de aumentar a disponibilidade de nutrientes (Luciano et al., 2014).

A fermentação em estado sólido ou em meio semissólido (FSS) é um processo fermentativo que ocorre na presença de conteúdo de água limitado, onde o crescimento microbiano e a formação de produtos ocorrem na superfície de substratos sólidos. O uso de resíduos agroindustriais em processos de FSS fornece uma alternativa economicamente viável a esses resíduos, que são na maioria das vezes subutilizados ou não utilizados (Singhania et al., 2009).

Entre os microrganismos utilizados na fermentação em estado semissólido, se encontra a levedura Saccharomyces cerevisiae, presente na nutrição humana e animal. Se destaca entre os microrganismos processadores de proteínas, devido a sua alta eficiência na conversão, relação não patogênica com o homem, além de ser reconhecida como fonte proteica, reserva natural de vitaminas do complexo B e D, aminoácidos em quantidade adequada e equilibrada, aproximando-se dos valores recomendados pelo padrão de referência da FAO e minerais (Muniz, 2017).

Diante do exposto, o objetivo deste trabalho foi estudar o processo de enriquecimento proteico do resíduo da goiaba com a utilização da levedura Saccharomyces cerevisiae, por meio de fermentação semissólida.

\section{Metodologia}

O trabalho foi conduzido no laboratório nos laboratórios da Unidade Acadêmica Tecnologia de Alimentos (UATA), no Centro de Ciências e Tecnologia de Alimentos (CCTA), da Universidade Federal de Campina Grande (UFCG), Campus de Pombal. De acordo com Pereira et al. (2018), a pesquisa teve natureza quantitativa por meio da coleta de dados experimentais e analisados por técnicas matemáticas.

\section{Matéria-prima}

A matéria-prima utilizada foi a sobra dos resíduos do processamento industrial do fruto da goiaba contendo restos da polpa, casca e sementes. Para o enriquecimento proteico foi utilizado o fermento biológico para processamento de pães e derivados, a levedura Saccharomyces cerevisiae desidratada, obtida no comércio local da cidade de Pombal, Paraíba.

\section{Fermentação semissólida}

A fermentação semissólida foi realizada de acordo com a metodologia descrita por Oliveira (2007), com adaptações.

O resíduo da goiaba foi triturado em processador afim de se aumentar a porosidade do leito e favorecer a fermentação uniforme em todo o material. Em seguida, colocou-se em um biorreator retangular com $1000 \mathrm{~g}$ do resíduo triturado em pequenas partículas e adicionou $12 \% \mathrm{~m} / \mathrm{m}$ da levedura, sendo espalhada em uma camada semelhante a uma placa plana, e acondicionado em uma estufa com circulação de ar forçada a $35{ }^{\circ} \mathrm{C}$ de temperatura, durante 21 horas. Foram feitas pesagens dessas amostras nos intervalos de 0,3, 6, 9, 12, 15, 18 e 21 horas de fermentação. 
Ao término da coleta de cada amostra, foram levadas a uma estufa de esterilização na temperatura de $55^{\circ} \mathrm{C}$, para que pudesse ocorrer a interrupção do processo fermentativo. Posteriormente, foram trituradas em um moinho de facas e armazenadas em temperatura ambiente em embalagens de polietileno.

\section{Análises físico-químicas}

Durante a fermentação semissólida foram monitorados em cada intervalo as análises do teor de água, proteínas e sólidos solúveis totais seguindo a metodologia do Instituto Adolfo Lutz (2008).

Para determinação do teor de água, o peso das amostras do resíduo enriquecido foi registrado em intervalos de tempos regulares utilizando uma balança analítica com uma precisão de $\pm 0,01 \mathrm{~g}$, ao final do processo a amostra do resíduo enriquecido foi colocada em uma estufa a uma temperatura de $105^{\circ} \mathrm{C}$, até atingir peso constante. $\mathrm{O}$ teor de água foi calculado pela razão da massa de água da amostra (g) em um tempo t sobre a massa total da amostra (g).

A determinação dos sólidos solúveis (em ${ }^{\circ}$ Brix) foram feitas em um refratômetro digital, onde em cada intervalo de tempo predefinido era recolhido uma parcela do produto para leitura. Enquanto o teor de proteína bruta foi determinado pelo método de Kjeldahl modificado, seguindo os Métodos físico-químicos de Análise de Alimentos (IAL, 2008).

\section{Resultados e Discussão}

As figuras a seguir demonstram os teores de água, sólidos solúveis e proteínas obtidos durante o período de secagem do resíduo da goiaba.

Observa-se na Figura 1 o comportamento do teor de água durante o período de secagem do resíduo, onde a fermentação iniciou com teor de água de $80 \%$ e este seguiu decrescendo até o vigésimo primeiro dia, chegando a 7,78\%. Esse comportamento foi semelhante ao de Silva et al., (2016) no estudo sobre enriquecimento proteico do resíduo de abacaxi mediante fermentação semissólida. De acordo com Fonseca et al., (2019) para a realização das atividades metabólicas do meio, necessita-se do consumo de água, fato esse, que explica o decréscimo deste teor. Outro fator que se explica a redução do teor de água é a incorporação do calor ao material, sendo este processo a desidratação, que ocorre com o fornecimento de calor ao produto úmido, a fim de remover por evaporação parte da água do material, produzindo um produto sólido suficientemente seco (Berk, 2018).

De acordo com Botelho et al. (2015) a redução do teor de água é uma operação favorável em produtos agrícolas, sendo uma alternativa importante, pois possibilita um armazenamento dos produtos de forma segura, podendo também promover a redução de mudanças qualitativas indesejáveis, tais como a descoloração, oxidação, trinca ou quebra dos grãos. Silva et al. (2016) ainda relata que essa diminuição do teor de água é de extrema importância para que ocorra uma concentração dos nutrientes no produto. 
Figura 1. Teor de água (\%) durante o período de secagem do resíduo.

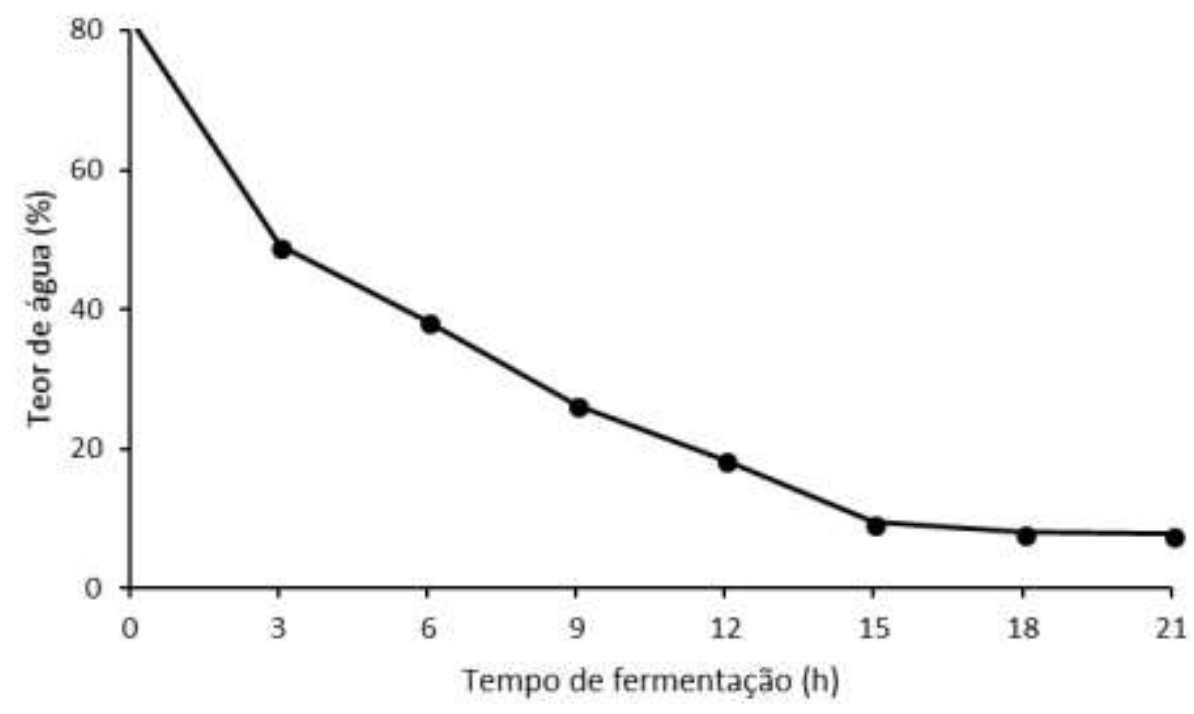

Fonte: Autores.

O consumo do açúcar durante a fermentação foi determinado através da análise de sólidos solúveis totais e apresentadas na Figura 2, no qual, percebeu-se uma diminuição gradativa do seu teor, visto que, durante o processo fermentativo as leveduras consomem o açúcar transformando-o em álcool. Os resultados encontrados neste trabalho foram superiores aos encontrados por Silva et al., (2017) em seu estudo sobre enriquecimento proteico de resíduo de umbu cajá empregando fermentação semissólida, onde obtiverem inicialmente um valor de $0,9 \%$ no tempo 0 , havendo redução durante o processo fermentativo para $0,5 \%$ no tempo de 72 .

Estudando o enriquecimento proteico do maxixe-bravo (cucumis dipsaceus ehrenb) por fermentação semissólida, França et al. (2020) encontraram um valor inicial de SST expressos em ${ }^{\circ}$ Brix foi de 2,9, no início da fermentação, decaindo com o passar das horas de observação, corroborando com o comportamento visto no presente estudo.

É importante ressaltar que a redução nos teores de sólidos solúveis durante o período de fermentação e secagem do resíduo era esperado, já que na fermentação semissólida os açúcares presentes no material são consumidos pelas leveduras para que assim ocorra o aumento proteico. 
Figura 2. Sólidos solúveis totais $\left({ }^{\circ}\right.$ Brix) durante o período de secagem do resíduo.

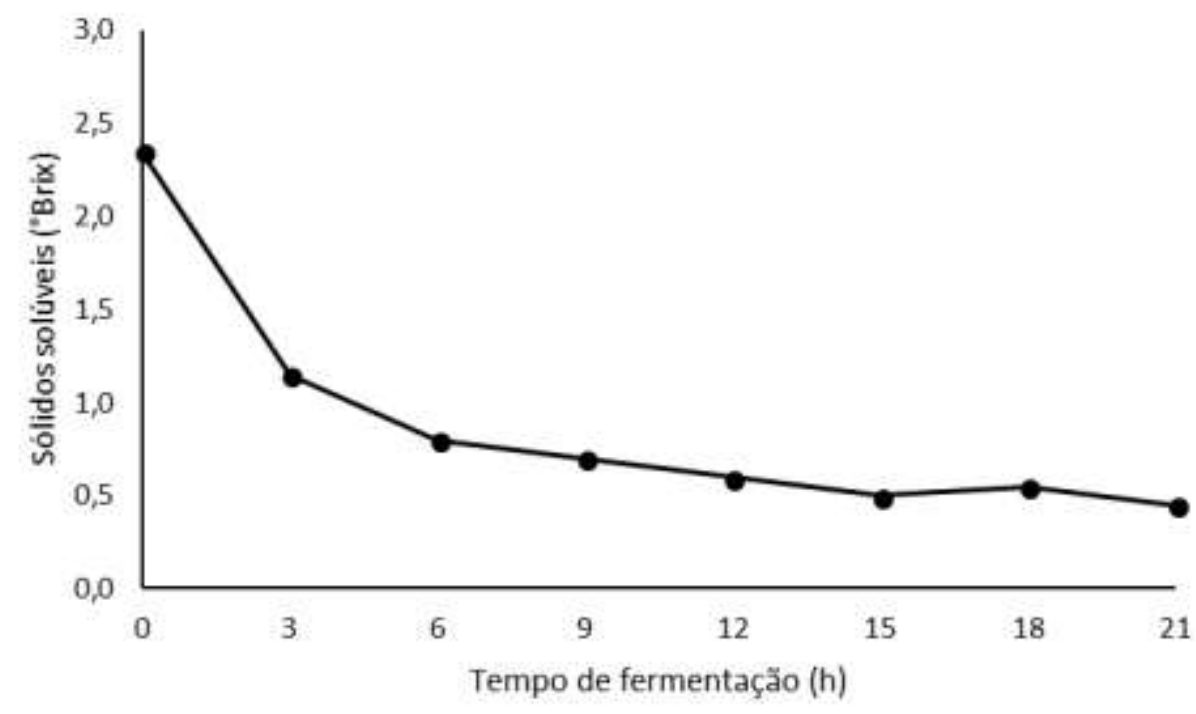

Fonte: Autores.

Na Figura 3 está expresso os teores de proteínas durante o período de secagem, onde foi encontrado um teor de 6,95\% no início do processo, aumentando com 3 horas e permanecendo estável de 6 até às 21 horas. Campos et al., (2018) também observaram um aumento no teor de proteínas do bagaço de caju e concluíram que o emprego da levedura (Saccharomyces cerevisiae) na fermentação semissólida do bagaço do pedúnculo de caju viabiliza a obtenção de um concentrado proteico, que poderá ser utilizado como fonte alternativa de alto potencial proteico, em ração animal. Alexandre et al. (2013) utilizando o mesmo microrganismo no enriquecimento do resíduo da casca de abacaxi (Ananas comosus L.), na temperatura de $34{ }^{\circ} \mathrm{C}$, durante 48 horas de processo, verificaram que o resíduo enriquecido também apresentou elevado teor de proteína (20,21\%) em relação ao resíduo in natura $(7,61 \%)$.

Figura 3. Teor de proteínas $(\%)$ durante o período de secagem do resíduo.

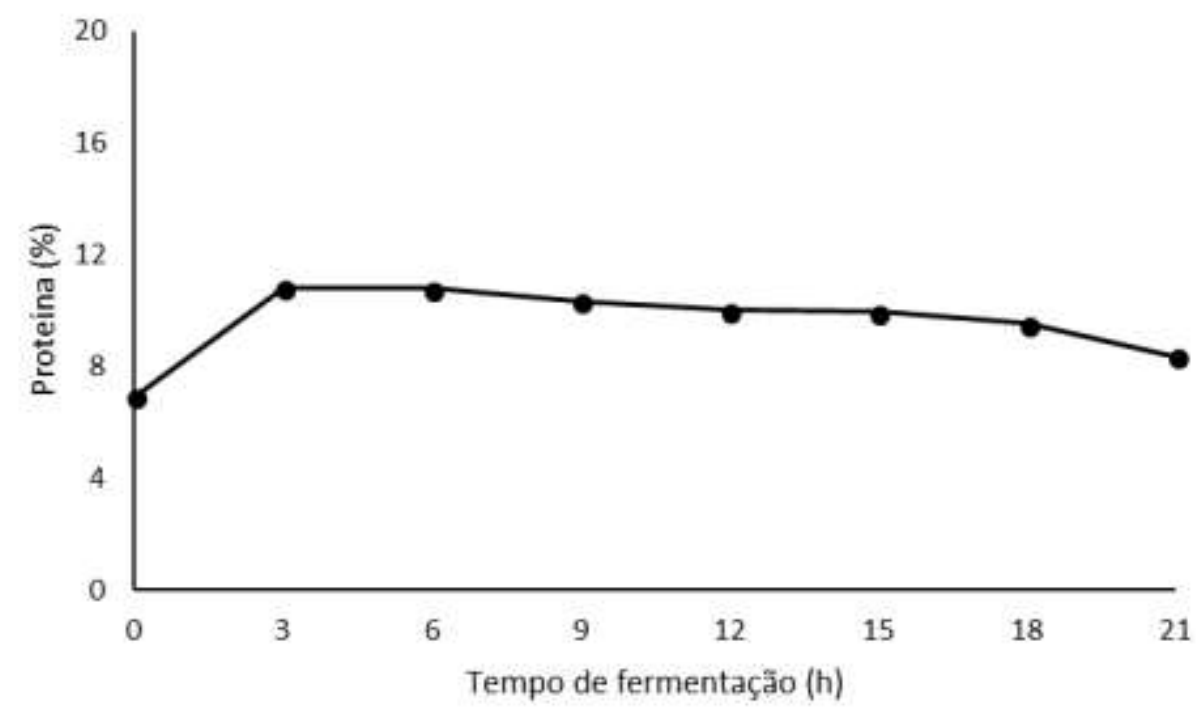

Fonte: Autores. 
O uso da fermentação semissólida tendo como objetivo o enriquecimento proteico de resíduos agroindustriais para a suplementação animal vem sendo estudada por diversos autores, que encontraram resultados satisfatórios no aumento de proteína ao final do período de fermentação, como é o caso de Hernándes et al. (2019) ao estudar a fermentação semissólida de palma (Opuntia spp) e Pinheiro et al. (2018) ao avaliar o enriquecimento proteico da palma forrageira com Saccharomyces cerevisiae para alimentação de ruminantes.

\section{Conclusão}

De modo geral é possível concluir que a fermentação semissólida empregada no resíduo da goiaba, com a utilização da levedura Saccharomyces cerevisiae, possibilitou o aumento no teor de proteína do resíduo com o tempo de fermentação, tendo as maiores concentrações às 3 e 6 horas. Assim é possível afirmar que a técnica empregada foi satisfatória no enriquecimento proteico do resíduo da goiaba, podendo ser utilizada como forma de aproveitamento de resíduos.

A aplicação do processo de enriquecimento proteico por via semissólida se mostra vantajoso, tendo em vista que os resultados encontrados se apresentaram de forma satisfatória ao aumento do conteúdo de proteínas no resíduo avaliado, podendo ser utilizado em outros produtos agroindustriais a fim de diminuir o desperdício.

\section{Referências}

Alexandre H. V., Silva F. L. H., Gomes J. P., Silva O. S., Carvalho J. P. D., \& Lima E. E. (2013). Cinética de secagem do resíduo de abacaxi enriquecido. Revista Brasileira de Engenharia Agrícola e Ambiental, 17, 640-646. https://doi.org/10.1590/S1415-43662013000600010

Berk, Z. Dehydration. In: Food Process Engineering and Technology. (3a ed.), Elsevier, 2018. https://doi.org/10.1016/B978-0-12-812018-7.00022-1

Botelho, F. M., Granella, S. J., Botelho, S. C. C., \& Garcia, T. R. B. (2015). Influência da temperatura de secagem sobre as propriedades físicas dos grãos de soja. Engenharia na agricultura, 23, 212-219. https://doi.org/10.13083/1414-3984/reveng.v23n3p212-219

Campos, A. R. N., de Santana, R. A. C., de Oliveira, L. C., Dantas, J. P., \& da Silva, F. L. H. (2018). Enriquecimento proteico do bagaço do pedúnculo de caju por levedura. In: IX Encontro Latino Americano de Iniciação Científica e V Encontro Latino Americano de Pós-Graduação-Universidade do Vale da Paraíba.

Costa Filho, D. V., Silva, A., Silva, P., \& Sousa, F. (2017). Aproveitamento de resíduos agroindustriais na elaboração de subprodutos. In II Congresso Internacional das Ciências Agrárias-COINTER-PDVAgro.

Fonseca, J. V. D. S., Andrade, M. D. L., Nogueira, L. P. D. S., Santos, J. D., \& Feitoza, J. V. F. (2019). Enriquecimento proteico de resíduo de frutas através de fermentação semi-sólida utilizando Saccaromyces cerevisae. Hig. Alim, 32(289), 604-608. https://higienealimentar.com.br/wp-content/uploads/2019_web2.pdf

França Silva, A. P., de Sousa, A. P. M., de Macedo, A. D. B., Dantas, D. L., Oliveira, J. A. M., de Almeida, A. F., \& Campos, A. R. N. (2020). Enriquecimento proteico do maxixe-bravo (Cucumis dipsaceus ehrenb) por fermentação semissólida. In: II Congresso Nacional de Pesquisa e Ensino em Ciências.

Hernández, A. F., Rodríguez, F. J. M., Herrera, C. M., Herrera, G. G., Arriaga, O. E., Salazar, J. O., \& Bautista, C. H. (2019). Fermentación semisólida del nopal (opuntia spp) para su uso como complemento proteico animal. Revista de Geografía Agrícola, 63, 87-100. https://doi.org/10.5154/r.rga.2019.63.04

Instituto adolfo lutz. (2008). Normas Analíticas: métodos químicos e físicos para a análise de alimentos. (4aed.), Instituto Adolfo Lutz.

Junior, R. G., Cavali, J., Porto, M. O., Ferreira, E., \& Stachiw, R. (2014). Resíduos agroindustriais e alimentação de ruminantes. Revista Brasileira de Ciências da Amazônia/Brazilian Journal of Science of the Amazon, 3(1), 93-104. https://periodicos.unir.br/index.php/rolimdemoura/article/view/1224/0

Luciano, R. C., Serralheiro, C., Araújo, L., Reis, A., Aguiar, E., \& Borba, L. (2014). Enriquecimento proteico de resíduos de abacaxi para alimentação alternativa de ruminantes. Revista Tecnologia \& Ciência Agropecuária, 8(4), 47-52. https://revistatca.pb.gov.br/edicoes/volume-08-2014/volume-8-numero-4outubro-2014

Muniz, C. E. D. S. (2017). Elaboração de barras de cereais utilizando resíduos agroindustriais de goiaba e caju enriquecidos proteicamente por via microbiana [Doutorado em Engenharia Química] Universidade Federal de Campina Grande.

Pereira, A. S., Shitsuka, D. M., Pereira, F. J., \& Shitsuka, R. (2018). Metodologia da pesquisa científica. UFSM. https://repositorio.ufsm.br/bitstream/handle/1/15824/Lic_Computacao_Metodologia-Pesquisa-Cientifica.pdf?sequence=1

Santos Pinheiro, L., Farias, T. J., \& Oliveira, F.H. (2018). Enriquecimento proteico da palma forrageira com saccharomyces cerevisiae para alimentação de ruminantes. Cadernos Macambira, 3(2), 17-18. https://www.scielo.br/j/abmvz/a/hcZb3G9bV9fr5S4JwNPHxnD/?format=pdf

SEBRAE. (2015). Serviço Brasileiro de Apoio às Micro e Pequenas Empresas. Boletim de Inteligência. Agronegócio Fruticultura. 
Research, Society and Development, v. 10, n. 14, e385101422050, 2021

(CC BY 4.0) | ISSN 2525-3409 | DOI: http://dx.doi.org/10.33448/rsd-v10i14.22050

Singhania, R. R., Patel, A. K., Soccol, C. R., \& Pandey, A. (2009). Recent advances in solid-state fermentation. Biochemical Engineering Journal, 44, 13-18. https://doi.org/10.1016/j.bej.2008.10.019

Souza Silva, G. M., da Costa, J. S., de Souza Cabral, M. D. C., de Lima, A. B. S., \& da Silva, O. S. (2016). Enriquecimento proteico do resíduo de abacaxi mediante fermentação semissólida. Revista Verde de Agroecologia e Desenvolvimento Sustentável, 11, 39-44. https://doi.org/10.18378/rvads.v11i5.4665

Silva, G. M. S., Costa, J. S., Filha, M. C. S. C., Lima, A. B. L., \& Silva, O. S. Enriquecimento proteico do resíduo de abacaxi mediante fermentação semissólida. Revista Verde,11,39-44. http://dx.doi.org/10.18378/rvads.v11i5.4665

Silva, J. L., da Silva, O. S., Alves, F. M. S., Vieira, N. C., \& do Nascimento, A. M. (2017). Enriquecimento proteico de resíduo de umbu-cajá empregando fermentação semissólida. Revista Verde de Agroecologia e Desenvolvimento Sustentável, 12(5), 854-857.

Sousa, M. S. B., Vieira, L. M., Silva, M. D. J. M. D., \& Lima, A. D. (2011). Caracterização nutricional e compostos antioxidantes em resíduos de polpas de frutas tropicais. Ciência e agrotecnologia, 35, 554-559. http://dx.doi.org/10.18378/rvads.v12i5.5572

Souza, H. A. D., Natale, W., \& Rozane, D. E. (2011). Avaliação agronômica da aplicação do resíduo da indústria processadora de goiabas em pomar comercial de goiabeiras. Revista Brasileira de Ciência do Solo, 35, 969-979. https://doi.org/10.1590/S0100-06832011000300031

Viana, L. G., \& Cruz, P. S. (2016). Reaproveitamento de resíduos agroindustriais. In Congresso Baiano de Engenharia Sanitária e Ambiental-IV COBESA. 